\title{
SSC gets new detector
}

\section{Washington}

SeVeral dozen institutions, most of them in the United States, have agreed to collaborate on building a new major detector for the Superconducting Super Collider (SSC). The detector, if it is approved by the SSC Laboratory, will take the place of the $\mathrm{L}^{*}$ (pronounced 'L-star') detector, which was cancelled last month because of problems with its funding and its management (see Nature 351, 258; 23 May 1991).

The physicists building the $\$ 8,200$ million SSC desire to have two separate major detectors that will observe the accelerator's particle collisions in complementary ways. One detector, being build by a group called the Solenoid Detector Collaboration, has already received approval from the SSC Laboratory; it will be a general-purpose detector designed to track large numbers of particles at once.

The cancellation of the $L^{*}$, which was intended to track fewer particles with greater accuracy, left the SSC with only one major detector in the works. In response, SSC Laboratory director Roy Schwitters invited all interested physicists to a Dallas meeting 11-13 June to discuss the possibilities for building a successor to the $\mathrm{L}^{*}$.

The meeting was as successful as Schwitters had hoped. By 18 June, a collaboration had formed that included most of the scientists that attended the meeting. The interim leaders of the group are Barry Barish of Caltech and Bill Willis of Columbia University.

The collaboration is still growing, Barish says, but already it has physicists from 35 to 40 institutions. They include "a good fraction of the high-energy physics community not involved in the other detector" and "almost everyone from $\mathrm{L}^{*}$ ", he says. Few of the institutions are from outside the United States, however, and Barish attributes this partly to the problems surrounding the $\mathrm{L}^{*}$ collaboration. Germany, Switzerland and the Soviet Union resigned from that collaboration, complaining that they were not being given enough respect.

To date, the major foreign partners in the new collaboration are China and Rumania, and Barish says the Soviet Union, Korea and Taiwan have also expressed interest. As time goes on, he says he hopes some European partners will materialize.

The group is proposing to build a detector that will do many of the same things that the $\mathrm{L}^{*}$ would have done. That makes sense, Barish notes, because the $\mathrm{L}^{*}$ was not cancelled for scientific reasons. In particular, the new detector will be designed to accurately identify and measure electrons and muons produced by collisions in the SSC. It will not be able to follow the tracks of the particles as accurately as the general-purpose detector, but it will provide more accurate information on the particles" properties.

Barish says the collaboration will be care- ful to avoid the cost problems that plagued the $\mathrm{L}^{*}$. The SSC Laboratory wants the two major detectors to cost no more than $\$ 500$ million each, but by the time of its cancellation, the price tag on the $\mathrm{L}^{*}$ had ballooned to more than $\$ 750$ million. (The cost of the general-purpose detector is now estimated at more than $\$ 700$ million, and its designers are now trying to pare it back.) Barish says his group is already discussing ways to keep the cost down without hurting performance, such as using a superconducting magnet, instead of non-superconducting as was planned for the $\mathrm{L}^{*}$, and not installing steel shielding around the magnet.

When the $\mathrm{L}^{*}$ was axed, Barish - who had played a major role in the collaboration quickly contacted many of the participants to ask them to try again. Within days of the cancellation, Barish held an informal meeting at Caltech with most of the principals plus others who had not been a part of the L*. "I felt that if there was any time lost at all, [the collaboration] would fall apart," he says. By the time of the meeting at the SSC Laboratory, the replacement was already mostly in place.

There remain a series of steps necessary before formal acceptance of the detector by the SSC Laboratory, but final approval seems a safe bet - this is the only good chance left to build a second detector for the SSC before its opening, now scheduled for 1999. Although Barish's group is starting a year late, he hopes to make up at least half of that and to be no more than six months behind the original schedule by next autumn, when the group should submit an engineering design report. "We expect to be there when the machine turns on." Robert Pool

\section{Bush salutes NIH at Healy's swearing-in}

\section{Washington}

BERnADINE Healy, the first woman to head the US National Institutes of Health, was officially sworn in this week at a ceremony with President and Mrs George Bush as the guests of honour. In a city in which symbols and reality are often one, the President's visit to the NIH campus in Bethesda, Maryland, on the outskirts of Washington, was meant to boost the morale of the nation's biomedical researchers, who feel mired in a financial crisis. The president called the NIH staff, from grants administrators to animal care staff, "unsung heroes" and said that "biomedical research is key to transforming the practice of medicine".

Healy, a Harvard cardiologist by training, also talked about the NIH's role in medicine. The purpose of all the fundamental work in molecular biology and other areas of basic research is "basically simple", she said. It is "saving lives". In emphasizing medical care as the ultimate goal of all research sponsored by the National Institute of Health, she reiterated a theme she struck during her confirmation hearings before the US Senate (see Nature 350, 178; 21 March 1991).

And she continued to present herself as a physician first and foremost with a story about a young woman in the late stages of metastatic breast cancer. Taking Healy's arm after a conversation about efforts in research, the woman said "Dr Healy, please hurry." Speaking to a crowd of several hundred guests at the swearing-in, Healy said, "I take that as my mandate."

Barbara J. Culliton

\section{ZOOLOGICAL RESEARCH}

\section{Zoo conservation plan}

\section{London}

THE House of Commons Environment Committee has endorsed proposals by the Zoological Society of London to save the threatened London Zoo by transforming it into a centre for conservation education.

In this form, the zoo would display fewer animals and would emphasize the work of the society's research arm - and in particular, the Institute of Zoology.

The zoo has been losing money for years, and in 1988 the government gave the Zoological Society - which runs the zoo - a grant of $£ 10$ million that was supposed to put the zoo back on its feet. But optimistic predictions of an upsurge in visitor numbers were not fulfilled, and the society announced earlier this year that the zoo would close unless more money were found.

On 9 July, the society's trustees must decide whether to close the zoo immediately or to use the remaining $£ 4.5$ million from the
1988 grant to implement a 3-year "phased withdrawal" from the Regents Park site.

The first option implies destruction of many of the zoo's animals, which the committee condemns as "totally unacceptable".

The second, says zoo director David Jones, would imperil the future of Whipsnade, the society's other zoo site, outside London, where some of the Regents Park animals would be rehoused.

If the society is successful in winning private sponsorship for a conservation centre, the House of Commons committee concluded that the government should provide some money to help implement the scheme. The committee noted that if the society were to close the Regents Park site, the government would still end up paying for it - the Department of the Environment, which leases the grounds to the society, could be faced with a bill of several million pounds to redevelop the site.

Henry Gee 